\title{
SMALL INDUSTRIAL-SCALE PRODUCER GAS UNITS
}

\author{
A. Bliek, W. P. M. van SWaAiJ and K. R. WesterterP \\ Department of Chemical Engineering, Twente University of Technology, PO Box 217, 7500 AE Enschede, The Netherlands
}

\begin{abstract}
The on-site generation of fuel gas from coal is one of the currently available technologies that may facilitate the reintroduction of indirect coal firing in industrial practice. In the present article the attention will be restricted to gasifiers with comparatively small unit capacities, producing low heatingvalue gas by gasification of coal with air. The article is intended to provide the reader with a broad review of the available technology, the implications of using coal-derived fuel gas as a substitute for conventional fuels, and the economic viability of on-site fuel gas generation.

On the basis of cost estimates, framed within the Western European situation, the competitiveness of low heating-value gas are discussed. A comparison is made between low and medium heating-value gas, natural gas and direct coal firing. Potential markets for low heating-value fuel gas are identified and discussed.
\end{abstract}

\section{INTRODUCTION}

At this moment, the major part of the industrial heat and power generating capacity is based upon the use of natural gas and fuel oil. Although two subsequent periods of sharply increasing crude oil prices have turned coal into a competitive fuel, the reintroduction of industrial coal firing has proceeded much slower than was anticipated only a few years ago. One of the factors that has contributed to this state of affairs is the fact that coal firing requires large investments in handling, storage and combustion equipment. Secondly, coal is not directly interchangeable with liquid or gaseous fuels. As long-term investments have been made in gas and fuel oil-fired equipment, the penetration of coal on the fuel market can only be expected to proceed slowly. Finally the "comeback" of coal is hampered because in most industries the skills and experience in coal handling and coal firing no longer exist.

Clearly, the problems associated with the reintroduction of coal can largely be overcome when coal is converted into a gaseous or liquid fuel, to which industry has become accustomed. In this respect one could think of the gasification and liquefaction of coal, but also of the production of so-called hybrid fuels, i.e. coal-water or coal-oil mixtures. In spite of large efforts made, the economic feasibility of these processes has remained highly uncertain up to now. For some time especially the large-scale production of synthetic natural gas from coal has been considered a promising technology. However, the huge investments involved in the erection of these plants, and the uncertain economic prospects have proven prohibitive in many cases.

In Europe, in particular, many proposed large-scale gasification projects have been postponed or cancelled altogether. As far as coal gasification is concerned, a less ambitious and more conventional approach may therefore have to be adopted. In this respect one may envisage a shift in attention towards the production of low and medium heating-value gas.

Medium heating-value (MHV) gas is usually obtained by gasification with oxygen, see Fig. 1 . This type of gas would typically be produced at a medium or large size, central gasification facility. The fuel gas could be transported by pipeline to various industrial customers. Hence, the gasifier would preferably be pressurized and the plant would incorporate extensive clean-up facilities in order to obtain a pipeline quality fuel gas. It still remains questionable whether these factors will allow MHV gas to be produced at acceptable cost levels.

For low heating-value (LHV) gas, produced by air gasification, the costs of air separation can be avoided. The low Wobbe index of this type of fuel gas tends to render pipeline transportation an unattractive option, and consequently it has to be produced on-site. Likewise this means that for most applications pressurization of the gasifier is not necessary and the gas quality standards can be relaxed. Finally, heat integration between the gasifier and the fuel gas consuming equipment is possible in a close-coupled arrangement. Although the gasification plant would in general be of a limited size, in which case the benefit of economy-of-scale is absent, the factors mentioned above may well result in a substantial reduction of the gas production cost. In this way coal gasification may come within the reach of industry.

The present article is intended to provide the reader with an overview of LHV gas production for

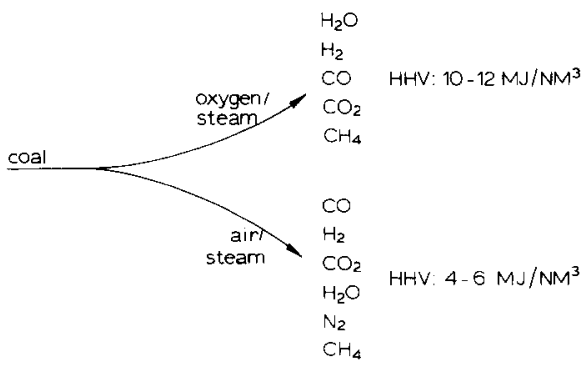

FIG. 1. Gasification by partial combustion. See Table 1 for typical gas compositions. 
industrial sites. In addition, basic data are presented to allow an assessment of the future role of on-site LHV-gas production. The suitability of commercially available gasification systems for small-scale, industrial applications will be discussed (Section 2). In Section 3 we will address the question of the interchangeability of LHV gas and natural gas in existing equipment. Finally, the economics of LHV gas production will be considered in Section 4, where gas cost data are presented for atmospheric pressure, airblown fixed-bed gasifiers. The competitiveness of LHV gas is considered on the basis of a comparison to MHV gas, natural gas and direct coal utilization. Conclusions will be drawn regarding the marketing potentials for LHV-gasifiers.

\section{COAL GASIFICATION; THE PROCESS AND THE TECHNOLOGY}

The process of coal gasification can be regarded as the donation of hydrogen or oxygen to a solid, carbonaceous fuel. In most gasification processes this is accomplished by partial combustion of coal with an air/steam or an oxygen/steam mixture. Other gasification principles will not be considered here.

In gasifiers which operate according to the principle of partial combustion, coal is oxidized with a substoichiometric amount of air or oxygen, to which steam is usually added. The energy required to convert steam into hydrogen is supplied by the exothermic oxidation of carbon to carbon monoxide. In this way an autothermal process is obtained, producing hydrogen and carbon monoxide as the major combustible products, although some methane is usually also produced. A large number of gasification technologies exist. As will be discussed below, the specific technology used for coal gasification may be of decisive influence on the field of application. Within the framework of the present study, the gasifier for small-scale industrial applications and various commercially available technologies will be discussed and compared. It is beyond the scope of the present article to present a review of all available gasification systems. The interested reader is therefore referred to various other sources for more comprehensive information. ${ }^{1.2}$

\subsection{Gasification Technologies}

Coal gasification technologies can be classified according to the type of reactor employed. The most prominent categories are the fixed-bed, fluidized-bed and entrained-bed variants, as shown in Fig. 2. Less important types, like the rotary kiln and the slag-bath gasifiers, will not be discussed as these are either still under development or they fall outside the range of the small gasifiers. ${ }^{8,17}$

Fixed-bed, actually moving-bed, gasifiers consist of a vertical shell with a rotating ash grate at the bottom. Usually fixed-bed gasifiers are operated in a countercurrent mode. In this design air is introduced at the
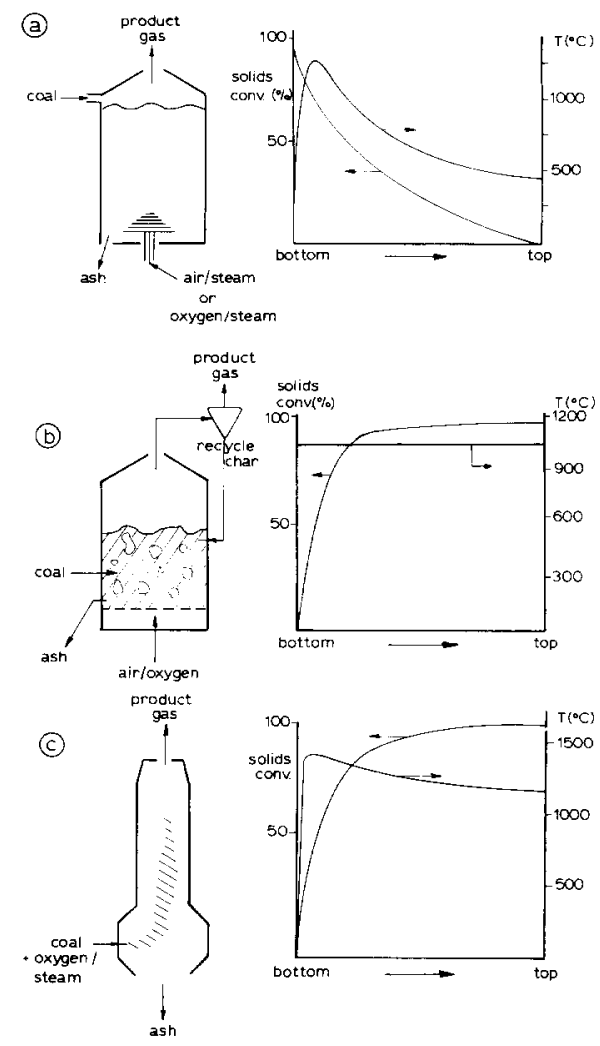

FIG. 2. Gasification technologies: (a) fixed bed; (b) fluidized bed; (c) entrained bed.

bottom and it flows upwards through the gasifier, see Fig. 2a. Due to this mode of operation the combustion zone of the gasifier is adjacent to the ash zone. Consequently, large amounts of steam have to be added to the gasifier in order to prevent ash melting. In this way the combustion zone temperatures can be reduced and controlled. Most of the steam merely passes through the gasifier, taking up sensible heat. A small part of the steam is converted into hydrogen. For this reason steam addition is accompanied by a substantial loss in efficiency. The volatile products are released from the coal in the upper section of the fuel bed, near the gas exit ports. Most of these volatile products, including tar and light hydrocarbons, end up in the product gas. For many applications the presence of these volatiles is undesirable and large investments have to be made in tar precipitation and gas scrubbing equipment. These gas treating procedures may result in a water pollution problem. In principle, tar removal from the product gas is not necessary in co-currently-operated coal gasifiers, which will be discussed later.

The operation and control of fixed-bed gasifiers is facilitated by the high carbon inventory in the gasifier, reducing the need for an instantaneous tuning of the air and coal feed rates. Fixed-bed gasifiers cannot handle large amounts of coal fines, and these have to be removed from the feed-coal. In view of the fact that, with present day mechanized mining techniques, the 
fines content of run-of-mine coal has increased, this is a rather serious drawback. In addition, strongly caking coals may not be acceptable, as these tend to agglomerate and block the gasifier. Development work is continuing to improve on the performance of fixed-bed gasifiers in this respect. ${ }^{3,4}$ At this moment these units are available as pressurized and oxygenblown variants, for instance from Lurgi Mineraloel Technik, but also as small airblown units, operated at atmospheric pressure. In fluidized-bed gasifiers, see Fig. 2b, crushed-coal particles are injected into a bed of inert material (ash) which is fluidized by the gasification air. An intimate contact between the solid and the gas-phase is thus obtained. In contrast to what is observed in fixed-bed gasifiers, the temperature is essentially uniform throughout the gasifier and the product gas exits are at approximately the bed temperature. In some fluidized-bed gasifiers, a zone of slightly higher temperature is created in order to bring about a controlled degree of ash-agglomeration. ${ }^{5}$ This is done because the removal of ash agglomerates from the bed material by gravity separation through the bottom is easier than the removal of ash fines from the product gas. However, it is difficult to obtain a good control of the ash agglomeration behavior. In nonagglomerating fluidized-bed gasifiers the mean temperature level has to be kept well below the ash softening point, which adversely influences the attainable throughputs, especially for low-reactivity coals. Coal is usually fed to a fluidized-bed gasifier through a large number of pneumatic injection points. The residual char, carried over from the bed, must be separated from the product gas and recycled to improve the overall carbon conversion efficiency. Clearly, both factors add to the complexity of the solid handling facilities. Also the waste heat recovery is usually more complex than with fixed-bed gasifiers. On the other hand, fluidized-bed gasifiers are more flexible with regard to the coal properties, as the coal particles are present in a dilute dispersion. The exception to this is the ash agglomeration behavior, which is a very important coal property for fluidized-bed gasifiers. An additional advantage of fluidized-bed gasifiers is the low specific tar production. ${ }^{5.7}$ An early version of the fluidized-bed gasification principle is the Winkler system, which has been under development since 1933 and is now marketed by Davy Powergas. ${ }^{9}$ It is reported that some seventy commercially-sized Winkler gasifiers have been installed to date $^{8}$ The Rheinische Braunkohle Werks are involved in a development program for a pressurized, oxygen-blown version of the Winkler system. ${ }^{7}$ Most fluidized-bed gasifiers which are currently under development are pressurized, oxygen-blown systems, typically intended for large-scale applications. ${ }^{8}$

The third major category of gasification reactors is formed by the entrained-bed variants, see Fig. 2c. In these units, finely ground coal is gasified in a pulverized fuel flame at very high temperature levels. Because the coal particles are in the pulverized fuel range, the carbon conversion rate is high and entrained-bed gasifiers can attain large specific coal throughputs. As a consequence of the high mean temperature level, entrained-bed gasifiers operate on the slagging regime and a part of the coal ash is removed at the bottom of the gasifier as a liquid slag. Residual ash droplets are entrained by the product gas and they solidify after the product gas is quenched by steam or cold recycle gas. Improper resolidification of coal ash can cause severe problems and an accurate temperature control is necessary to prevent this. In turn, this calls for a precise tuning of the coal and air feed rates. Due to the elevated product gas temperatures, an extensive downstream waste heat recovery system is required. In addition, residual fly-ash must be removed. Because of the high gasification temperature, the tar content of the product gas is extremely low, and no tar removal systems are necessary. ${ }^{10,11,12}$

The combination of the gasification technology and the type of fuel gas produced, either LHV or MHV gas, may have a major impact on the choice of coal gasifiers. For off-site utilization of the product gas, involving pipeline transportation and extensive upgrading, large-scale, oxygen-blown and pressurized gasification units will be employed. In contrast, atmospheric pressure and air-blown units are the most economical solution for on-site fuel gas generation. Such decentralized systems are likely to be comparatively small, and this sets limitations to the gasification technology. For small gasifiers the gas treating and the solids handling procedures must be limited. The gasifier should be of a simple design and the operation and control must be easy. In the light of these conditions some conclusions can be drawn with regard to the suitability of the three gasification technologies discussed above.

Entrained-bed gasifiers require an extensive downstream gas treating and waste recovery section. The operation of the gasifier is complicated by the extremely small carbon hold-up, necessitating an accurately-controlled coal feed rate. These factors essentially rule out the application of entrained-bed gasifiers on a small scale. This is illustrated by the fact that the commercially available Koppers-Totzek gasifier is manufactured as a commercial unit of around $200 \mathrm{MW}_{\mathrm{th}}$ (megawatts thermal). ${ }^{12}$ The Shell

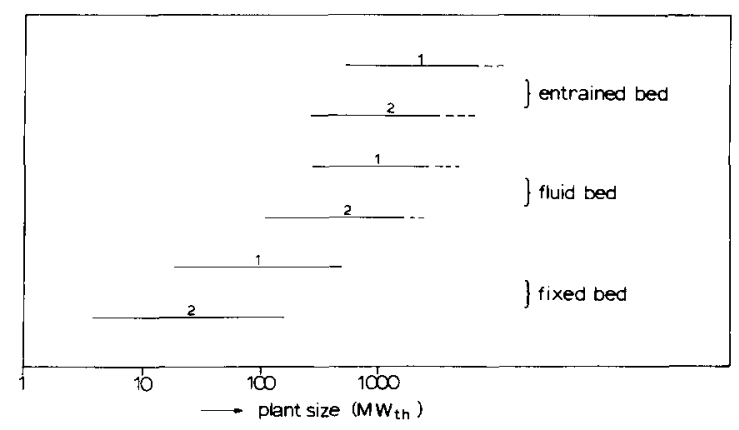

FIG. 3. Likely capacity ranges for commercially-sized gasification units: (1) oxygen blown; (2) air blown. 
and the Texaco entrained-bed gasifiers, under development for high pressure, oxygen-blown operation, may eventually be applied at still larger unit capacities. ${ }^{10,11}$

A comparison between fluidized-bed and fixed-bed gasifiers shows that both types have specific advantages and disadvantages, as far as the application on a small scale is concerned. Fluidized-bed gasifiers require a rather complex coal feed and char recycle system and, especially when high-rank coals are utilized, the operation and control may be complicated. On the other hand, fixed-bed gasifiers require a tar-precipitation step, which adds considerably to the plant investment. Industrial practice has shown that fixed-bed gasifiers can be applied at very small unit capacities. An analogy probably exists between gasifiers and coal-fired boilers, where stoker-fired, fluidized-bed and pulverized-fuel units are applied at a successively increasing scale of operation. In a qualitative sense this analogy is reflected in Fig. 3.

At this moment only fixed-bed gasifiers are available commercially at fairly small unit capacities. In view of the specific features of these units this may remain so for the near future. This conclusion has led us to present a more detailed discussion of the fixedbed gasifier, and to select this type for a more detailed economic analysis.

\subsection{Fixed-Bed Producer Gas Units: State of the Art}

Fixed-bed producer gas units, defined here as airblown, atmospheric pressure gasifiers, have been manufactured and used for over a century. ${ }^{3,8}$ The basic patents have since long run out and the design of these units is well established. At this moment only a limited number of manufacturers is still active in the field. Among them, Lurgi Mineraloel Technik is without doubt the most prominent one. This firm has now concentrated largely on the development of oxygen-blown and pressurized fixed-bed gasifiers. Producer gas units are available from Wellman, ${ }^{14}$ Woodall-Duckham/IGI ${ }^{13}$ and some firms with smaller involvements in this area, like Foster Wheeler/ Stoic, ${ }^{16}$ Riley ${ }^{15}$ and Gaz Integrale. ${ }^{53}$ Currently an estimated total of 50 coal-based producer gas units are in operation throughout the world, mainly in South Africa, the U.S.A. and various developing countries. Wellman claims to have installed some forty units since $1963 .{ }^{14}$ The construction of fourteen fixed-bed units has been either completed recently or is under construction in the U.S.A. ${ }^{8,18}$ In part these gasifiers are funded by the "Gasifier in Industry" program, initiated in 1976 by the U.S. Energy Research and Development Authority, predecessor of the Department of Energy. ${ }^{3,18}$ With this Federal funding the suitability of producer gas units for industrial applications is to be demonstrated. Along with the erection of new, commercially-sized plants, more advanced fixedbed gasifiers are under development, like the M.E.R.C., G.E.C. and G.F.E.T.C. versions. ${ }^{3,18,19}$

In Western Europe the market situation is less favourable, due to comparatively high indigenous coal prices. The authors know of only one project in this field which is currently underway in Western Europe, namely the construction of a 2-unit Gaz Integrale gasification plant at the Carmeuse lime kilns in Belgium. ${ }^{20}$

\subsubsection{Layout and operation}

The oldest version of the fixed-bed producer gas unit is the single-stage counter-current variant, see Figs $4 \mathrm{a}$ and $5 \mathrm{~b}$. In this design an air/steam mixture is admitted at the bottom of the gasifier, where it burns out the residual carbon of the down-flowing coal. From this oxidation zone the gaseous combustion products and steam flow upward to the reduction zone, where they react with the fixed carbon of the coal, forming a mixture of carbon monoxide and hydrogen. At the top of the gasifier the hot gas mixture takes up the volatile products, released from the coal in this area. The volatiles-tars and lighter hydrocarbons-are heated by the direct contact with the hot reduction-zone gases. Inevitably this results in cracking and repolymerization reactions of the tar,
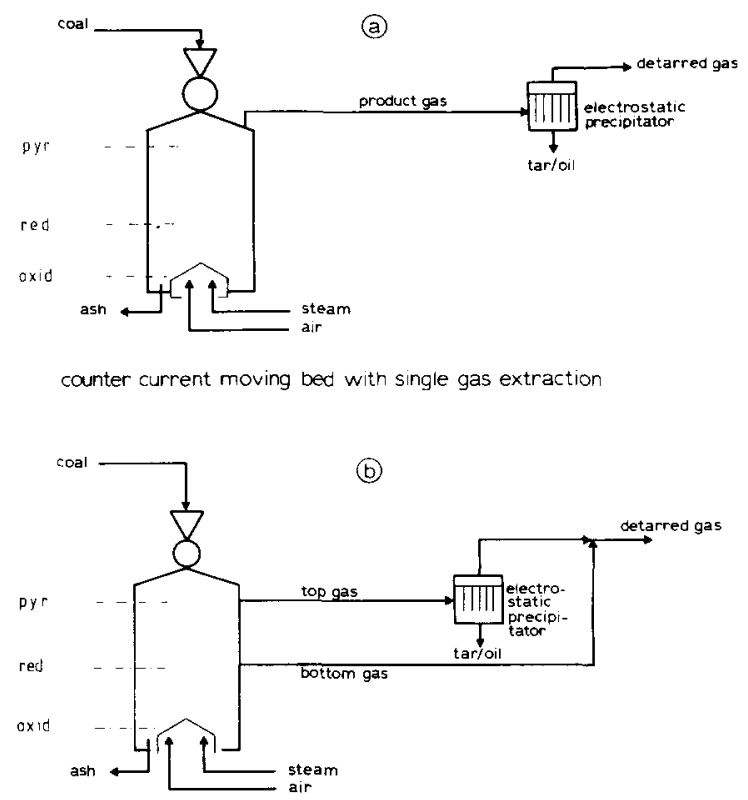

counter current moving bed with double gas extraction

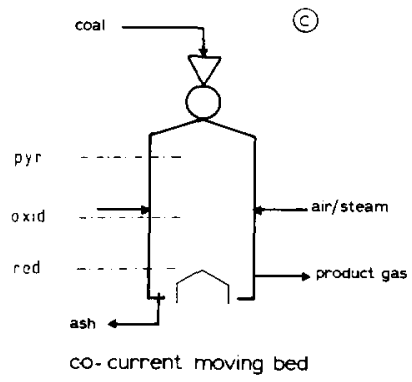

FIG. 4. Operating modes for fixed-bed gasifiers. 


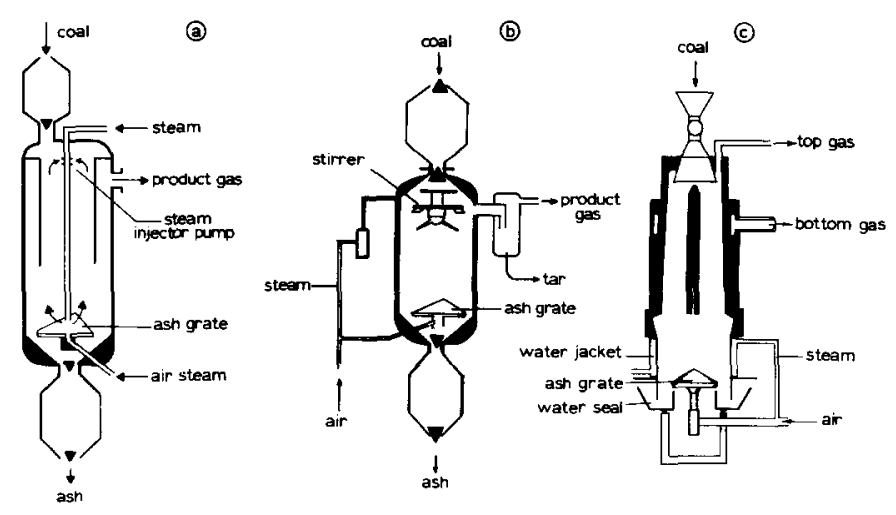

FIG. 5. Layout of various fixed-bed gasifiers: (a) single-stage gasifier with internal tar-recycling, K.G.N.design ${ }^{23}$; (b) single-stage gasifier, Lurgi-design ${ }^{6}$; (c) double-stage gasifier, supplied by various firms.

which becomes highly viscous and rich in soot. This phenomenon has made tar removal from the product gas one of the major, traditional problems of singlestage, counter-current flow gasifiers.

Much work has been done to overcome the difficulty of tar and oil removal from the product gas of fixed-bed gasifiers. This has resulted in the development of the two-stage gasifier (Figs $4 b, 5 c$ ), where a direct contact between reduction-zone gases and coal volatiles is prevented by using separate extraction ports for these products. Consequently, the coal volatiles remain comparatively cool, and the tar quality is improved with respect to its fouling and flow properties. The basic advantage of heat exchange between the incoming coal and the product gas is largely lost in this design. Whereas two-stage units are manufactured by Wellman, Foster Wheeler/Stoic and Woodall Duckham, the commercially available Lurgi gasifier is still of the single-stage type, see Fig. $5 \mathrm{~b}$. Interestingly, Lurgi has also adopted the two-stage concept for its experimental Ruhr-100 gasifier. ${ }^{21}$

Along with the development of the two-stage concept, various other solutions for the tar problem have been attempted. In the Kohle Gas Nordrhein gasifier, Fig. 5a, an internal recycling system is utilized to transport coal volatiles toward the combustion zone of the gasifier. ${ }^{23}$ This procedure is not new. Extensive try-outs with external tar recycling systems were reported at the beginning of this century. ${ }^{24}$ At that time, air-jet blowers were utilized and many problems were experienced, like fouling of transport lines and ash-clinkering near the combustion zone. In the K.G.N. concept the coal volatiles are recycled internally by steam injection. The use of steam prevents ash clinkering, because the combustion zone temperatures are reduced. An essentially tar-free product gas is claimed to be obtained with this recycling system. ${ }^{23}$

Internal conversion of tarry components can also be achieved by operating the gasifier in a co-current mode, see Fig. 4c. In this design, the combustion zone is located at or near the top of the gasifier, whereas the product gas is extracted at the bottom. Hence, all tarry components are forced to pass through the combustion zone of the gasifier, which results in a nearcomplete conversion by a combination of combustion and cracking reactions. ${ }^{25}$ Often co-current gasifiers contain a locally narrowed shaft section, the so-called throat, which acts to stabilize the combustion zone. This throat presents a scale-up problem, and up to now the co-current concept has only been applied for biomass gasifiers with unit capacities up to $4 \mathrm{MW}_{\mathrm{th}}{ }^{26}$ For coal the use of such a throat may not be necessary and consequently scale-up need not be a problem. An additional advantage of co-current operation is that the combustion zone is situated at a considerable distance from the ash zone. Hence, clinkering problems are absent and the gasification air can easily be distributed over the gasifier cross-section by injecting it above the fuel bed ${ }^{25}$ (Fig. 6).

The specific coal throughputs of fixed-bed producer gas units are considerably lower than those reported for oxygen-blown and pressurized variants, see Fig. 7. In view of the maximum vessel diameter available, currently about $3.6 \mathrm{~m}$ internal diameter, the maximum output is about $15 \mathrm{MW}_{\mathrm{th}}$. Beyond this capacity level a multiple-unit set-up is required.

As discussed above, the mode of operation of fixedbed gasifiers is to a large extent governed by the problem of tar formation. At present only counter-

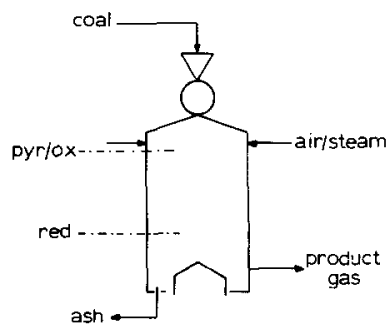

Cocurrent moving bed with combined pyrolysis oxidation zone.

FIG. 6. Co-current fixed-bed gasification with air introduction above the fuel bed. ${ }^{25}$ 


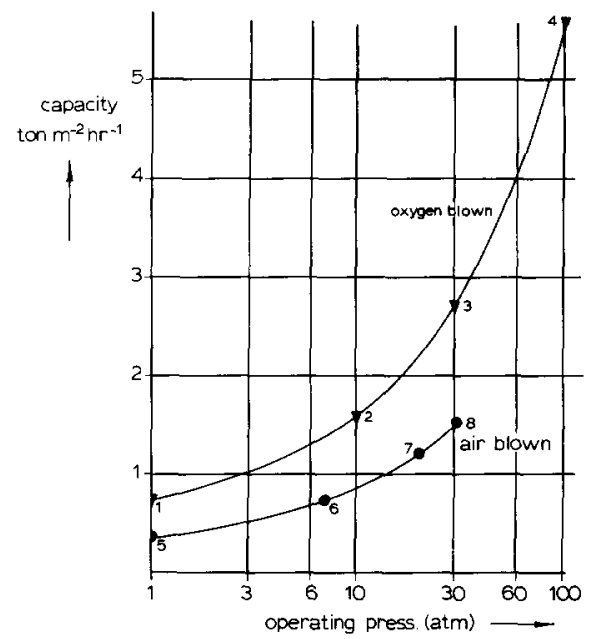

FIG. 7. Specific hard-coal throughputs of nonslagging fixedbed gasifiers: (1) Ref. 22; (2) Ref. 22; (3) Refs 4, 6, 22; (4) Ref. 21; (5) Refs 8, 16, 22; (6) Ref. 3; (7) Refs 3, 19; (8) Ref. 23, anticipated value.

current fixed-bed gasifiers are available commercially, as single-stage and as two-stage variants. The operational experience gained with these gasifiers is considerable and they are used in many different applications. Often they are installed in a closecoupled arrangement, supplying gas directly to boilers, kilns, or furnaces, see Fig. 8 . When the gas is fueled to combustion equipment at a low temperature level, an intermediate tar separation must be included. However, even when the product gas is delivered hot, tar fouling problems are sometimes reported..$^{42}$

In a close-coupling arrangement the load-following behavior and turn-down ratio of the gasifier are of crucial importance, as an intermediate gas storage is both impractical and very costly. Recent studies on an air-blown Lurgi gasifier indicate that this unit can follow load changes of $-20 \%$ at a ramprate of $4 \% /$ min. $^{27}$ Both Foster-Wheeler and Wellman also claim excellent load-following behavior for their fixedbed gasifiers, but quantitative data are not presented. ${ }^{14,16,28}$ The load-following behavior as well as the turn-down ratio of fixed-bed producer gas units, frequently reported to be $1: 3$ to $1: 6$, seem to be acceptable for most applications.

Small industrial gasifiers are likely to be of the fixed-bed type. From this category, the countercurrent flow variant has been available for a long time and a good deal of experience has been gained with it. Most manufacturers claim plant availabilities in excess of $80 \%$ and they offer various forms of operating guarantees. Fixed-bed gasifiers can favourably be used in a close coupled arrangement, preferably supplying hot gas. However, in various cases the product gas must be cooled, as from a technical point of view the direct firing of hot gas is not always feasible. Also the environmental impact may be unacceptable..$^{29,30,31,32}$ As all commercially available desulfurization processes operate at a low temperature level, extensive gas treating implies the intercooling of the product gas. As will be discussed later, this may seriously influence the economic viability of the gasification process.

\section{COAL-DERIVED FUEL GAS AS A SUBSTITUTE FOR CONVENTIONAL FUELS}

\subsection{General Aspects}

The use of coal-derived fuel gases in existing process equipment may have far-reaching implications, as LHV gas in particular differs in many respects from conventional fuels. For this reason it is worthwhile to consider the combustion characteristics of various coal-derived fuel gases. Some typical examples of such fuel gases, with compositions as indicated in Table 1, will be used in our calculations.

The flame stability of fuel gases is characterized by the limits of flash-back and lift-off. In view of the heating value of coal-derived fuel gases, the fuel gas

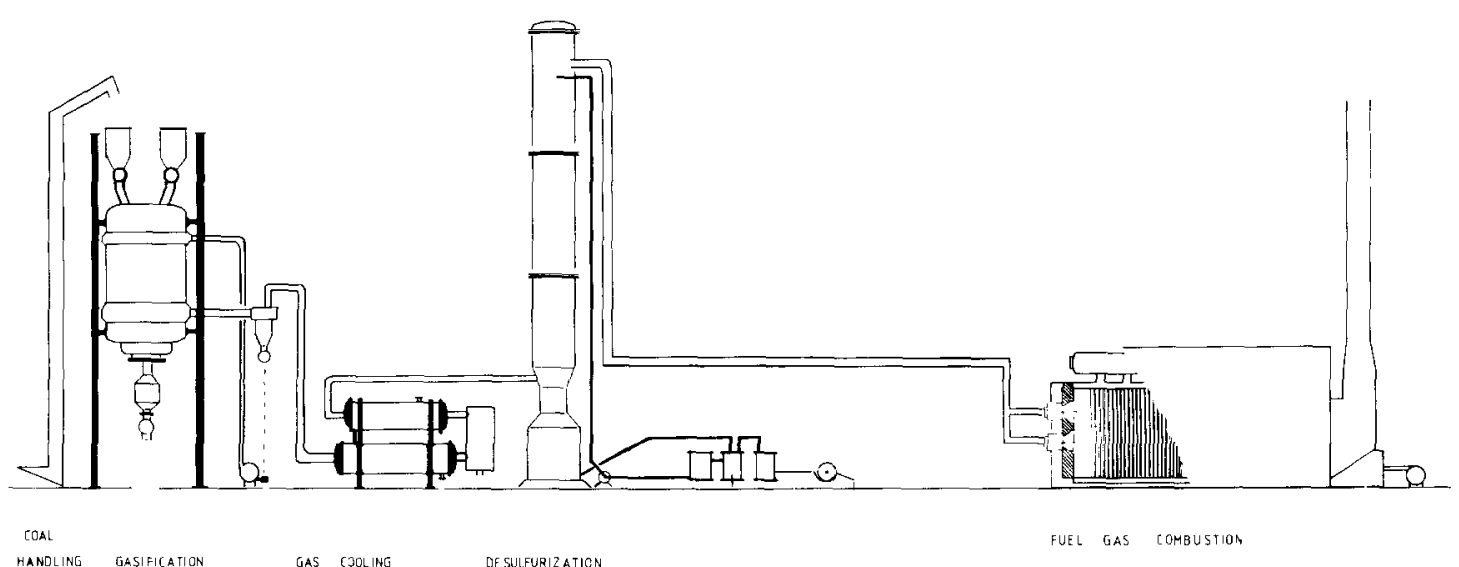

FIG. 8. Layout of a gasifier/boiler plant in a close-coupling arrangement. 
TABLE 1. Typical dry gas compositions of various coal-derived fuel gases

\begin{tabular}{lcccccc}
\hline & $\begin{array}{c}\mathrm{CO} \\
(\mathrm{vol} \%)\end{array}$ & $\begin{array}{c}\mathrm{CO}_{2} \\
(\mathrm{vol} \%)\end{array}$ & $\begin{array}{c}\mathrm{N}_{2} \\
\left(\mathrm{vol}_{0} \%\right)\end{array}$ & $\begin{array}{c}\mathrm{H}_{2} \\
\left(\mathrm{vol}_{0} \%\right)\end{array}$ & $\begin{array}{c}\mathrm{CH}_{4} \\
(\mathrm{vol} \%)\end{array}$ & $\begin{array}{c}\mathrm{HHV} \\
\left(\mathrm{MJ}^{2} / \mathrm{Nm}^{3}\right)\end{array}$ \\
\hline 1. Texaco, oxygen & 52 & 9 & 1 & 38 & 0 & 11.4 \\
2. Wellman, oxygen & 52 & 12 & 2 & 33 & 1 & 11.2 \\
3. Wellman, air & 29 & 3 & 50 & 16 & 2 & 6.6 \\
4. Winkler, air & 22 & 10 & 55 & 12 & 1 & 4.7 \\
5. Combust. Engng, air & 22 & 5 & 60 & 11 & 0 & 4.2 \\
6. Natural gas* & - & - & 10 & - & 90 & 35.5 \\
\hline
\end{tabular}

* Example for reasons of comparison.

TABLE 2. Gas, air and flue-gas flows based upon $25 \mathrm{MW}$ input

\begin{tabular}{lccc}
\hline & $\begin{array}{c}\text { Fuel gas } \\
\left(\mathrm{NM}^{3} / \mathrm{sec}\right)\end{array}$ & $\begin{array}{c}\text { Air flow } \\
\left(\mathrm{NM}^{3} / \mathrm{sec}\right)\end{array}$ & $\begin{array}{c}\text { Flue gas } \\
\left(\mathrm{NM}^{3} / \mathrm{sec}\right)\end{array}$ \\
\hline 1. Texaco, oxygen & 2.19 & 5.21 & 6.44 \\
2. Wellman, oxygen & 2.24 & 5.38 & 6.57 \\
3. Wellman, air & 3.68 & 5.31 & 8.14 \\
4. Winkler. air & 5.32 & 4.88 & 9.25 \\
5. Combust. Engng, air & 5.95 & 5.19 & 9.66 \\
6. Natural gas & 0.704 & 6.70 & 7.42 \\
\hline
\end{tabular}

The data given are based upon a $10 \%$ excess air level, and fuel gas compositions as given in Table 1 .

flow must be increased as compared to conventional fuels, such as natural gas. This can only be realized without flame stability problems when the burner nozzles are modified. The minimum injection velocities of $\mathrm{LHV}$ and $\mathrm{MHV}$ gas must be somewhat higher than in the case of natural gas, as a consequence of the enlarged flame velocities caused by the presence of hydrogen. With a modified burner, flame stability problems can in general be avoided. ${ }^{34,36,35}$ The presence of hydrogen is responsible for extended flammability limits and a facilitated ignition behavior. The turn-down ratio of the burner may therefore be higher than in the natural gas-fired case.

In boilers and furnaces the flame length may be an important parameter. Extensive investigations at the Institute of Gas Technology (Chicago, U.S.A.) have shown that the flame length is largely dominated by the mixing behavior of the fuel gas and the combustion air. ${ }^{35}$ If the fuel-to-air momentum ratio is about unity, the mixing becomes sore and flames tend to be long. For LHV and MHV gas, the fuel-to-air mass flux ratio differs considerably from that of natural gas, see Table 2 . Hence, the gas and air nozzles of the burner have to be adapted. Experimental data from the Institute of Gas Technology indicate that this may indeed result in nearly unchanged flame lengths, when natural gas is replaced by LHV or MHV gas. ${ }^{36}$

In many industrial applications, such as in open hearth and glass furnaces, high furnace temperatures are required. In such cases the use of LHV gas may present problems, in view of the low adiabatic flame temperature (Fig. 9). This difficulty can be overcome by using hot gas directly from the gasifier, or by preheating the combustion air. For MHV gas the flame temperatures are high, sometimes even higher than with natural gas, and therefore this gas is wellsuited to obtain high furnace-room temperatures. As will be discussed later, the low flame temperature of LHV fuel gases has a considerable impact on the radiative heat-transfer characteristics. For instance in the case of boilers, the heat absorption pattern may therefore be changed drastically.

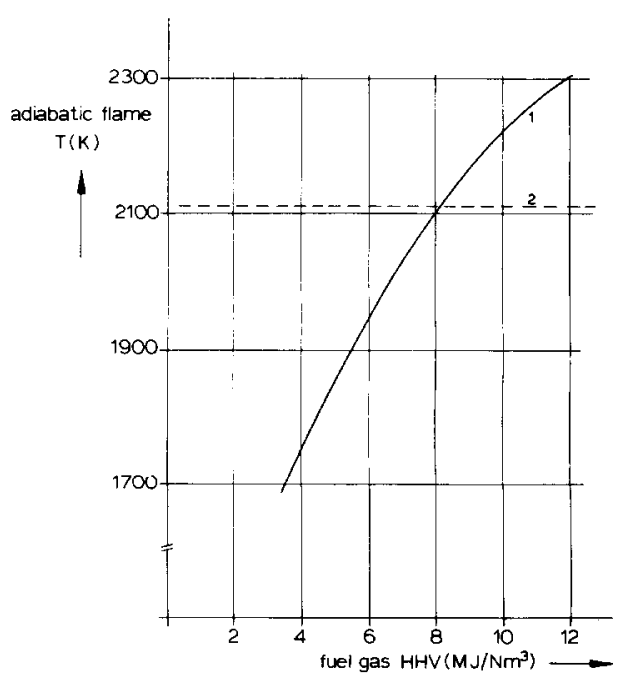

FIG. 9. Approximate adiabatic flame temperatures at $10 \%$ excess air level and fuel gas compositions as in Table 1. [1: coal-derived fuel gas, 2 : natural gas]. 


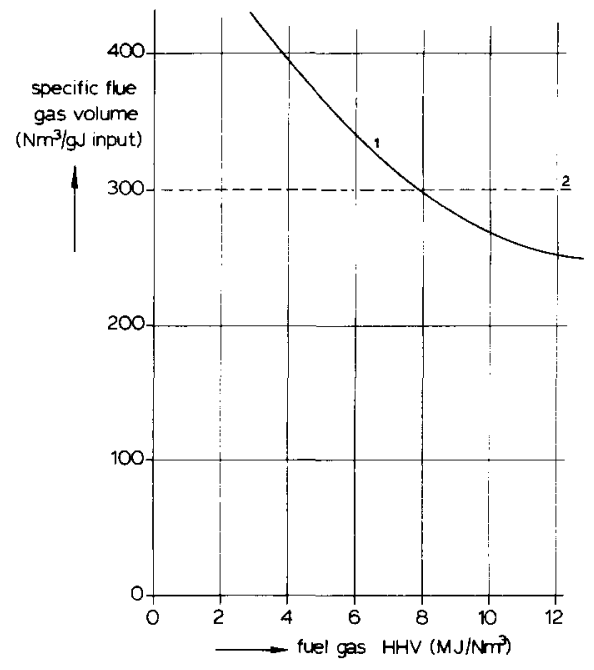

F1G. 10. Specific flue-gas volume at $10 \%$ excess air level and fuel gas compositions as in Table 1. [1: coal-derived fuel gas, 2: natural gas].

Yet another point of interest is the equipment rating. The equipment rating is usually governed by the heat absorption pattern and by the allowable fluegas flow. As is indicated in Fig. 10, the specific flue-gas volume for 4 to $6 \mathrm{MJ} / \mathrm{NM}^{3} \mathrm{LHV}$ gas can be $10-40 \%$ larger than for natural gas. In boilers, larger flue-gas flows can sometimes be accommodated only when induced-draft fans and flue-gas ducts are replaced. This depends on the specific boiler design and is discussed more fully by others. ${ }^{38,39,40,41}$ If an increased flue-gas flow rate is unacceptable, the equipment must be derated. For a mean quality LHV gas of $6 \mathrm{MJ} / \mathrm{NM}^{3}(160 \mathrm{Btu} / \mathrm{ScF})$, the derating will in general not exceed around $15 \%$ (Fig. 10). When LHV gas is applied in kilns, derating may not be necessary. ${ }^{42}$

A special case arises when the use of LHV gas in gas turbines is considered. Current gas turbine technology requires that the inlet temperatures are kept below approximately $1000^{\circ} \mathrm{C}^{43}$ With conventional fuels, this is accomplished by using large excess air levels, typically around $250 \%$. The excess air level can be reduced when LHV gas is used, and the gas turbine can be operated on a similar rating as with natural gas. The application of atmospheric pressure-producer gas units to fuel gas turbines would involve a gas cooling and compression step. An example of such a set-up is the proposed Combustion Engineering Combined Cycle. ${ }^{43,44}$ For small capacity ranges, this option is not likely to be economically feasible and it will therefore not be discussed further.

\subsection{Firing Coal-derived Fuel Gas in Industrial Boilers}

Industrial fuel consumption is used to a considerable extent for steam generation. Therefore a more detailed discussion of the performance of industrial steam and hot-water boilers seems justified. In order to establish performance data for this type of equipment, detailed calculations have been carried out for a $25 \mathrm{MW}_{\text {th }}$ hot-water and steam boiler. Details of the calculations will be presented elsewhere. ${ }^{25}$

The adiabatic flame temperature of LHV fuel gas is quite low. When a natural gas-fired boiler is switched to LHV gas firing, the heat absorption pattern will therefore shift. A quantitative assessment of this phenomenon was made by means of a simulation model of the radiation and convection sections of two boilers.

The radiation section of the boiler was modeled on the basis of the "Nonwell-Stirred Speckled-Wall Model", presented by the Institute of Gas Technology ${ }^{46}$ as a modified version of an earlier model, published by Hottel. ${ }^{45}$ In this model the radiation section is considered pseudo-well stirred. Carbon dioxide and water vapor are assumed to be the only gaseous species that contribute to radiation and both components are considered interactively. The heat absorption in the convection sections of the boiler is calculated on the basis of the assumption of plug flow for the flue gases.

Model predictions have been compared to experimental observations for a $27 \mathrm{MW}_{\text {th }}$, natural gas-fired

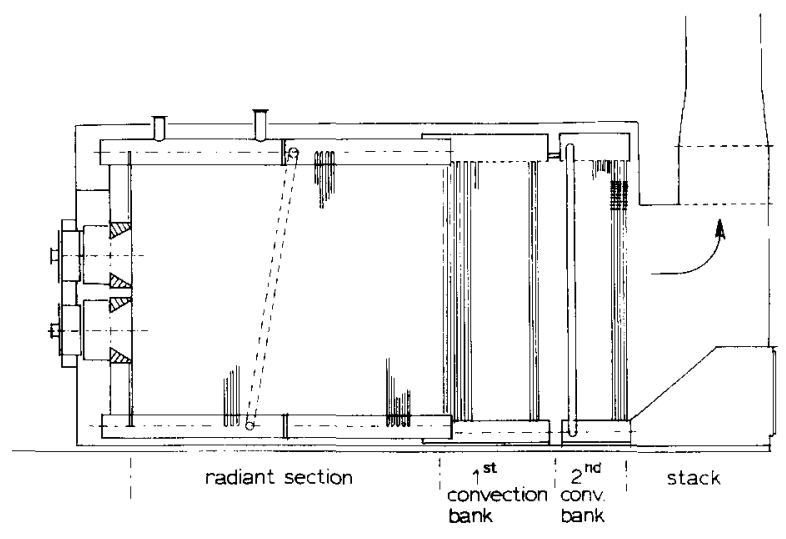

Fig. 11. Schematic representation of the $27 \mathrm{MW}_{\text {th }}$ hot-water boiler of the "Vrije Universiteit", Amsterdam, which was used to verify model predictions. 


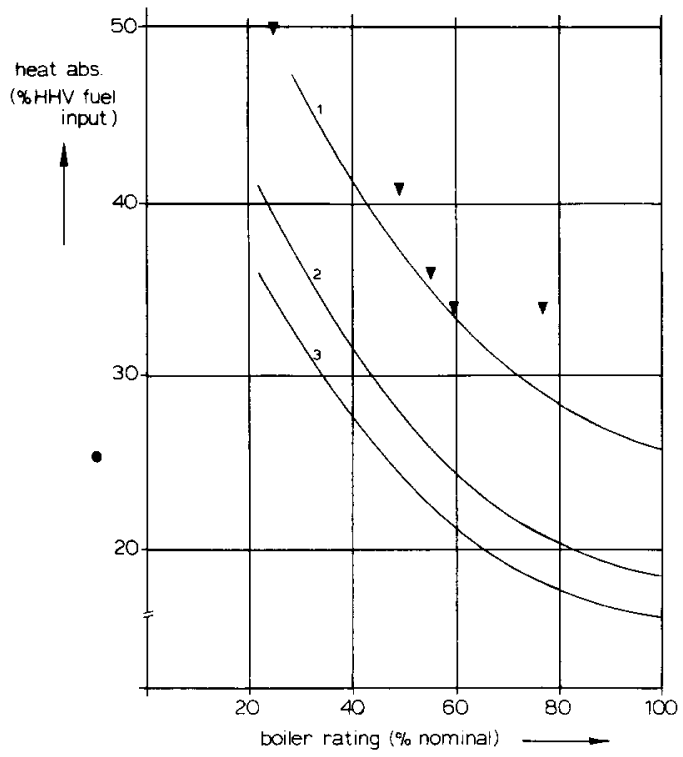

FIG. 12. Radiant section efficiency of a $27 \mathrm{MW}_{\mathrm{th}}$ hot-water boiler: (1) model predictions on natural gas (see Table 1); (2) model predictions on combustion engineering LHV fuel gas, fed at $800^{\circ} \mathrm{C}$, see Table 1 ; (3) model predictions on Winkler LHV gas, fed at $20^{\circ} \mathrm{C}$, see Table 1. $\nabla$ : Experimental observations on natural gas.

hot-water boiler, situated at the energy centre of the "Vrije Universiteit" in Amsterdam, Holland. This is a one-track, horizontal water-tube boiler, indicated in Fig. 11. The calculated heat absorption patterns for the boiler, fired with natural gas and LHV gas, are presented in Figs 12 and 13. Experimental data for the natural gas-fired case have been added for comparison. For this hot-water boiler it can be observed that the radiation section efficiency drops when natural gas is replaced by LHV gas. Consequently, the load pattern shifts towards the convection banks. However, the overall efficiency is hardly affected, which is partly a consequence of the comparatively low water vapor content of the flue gases in the LHV gas-fired

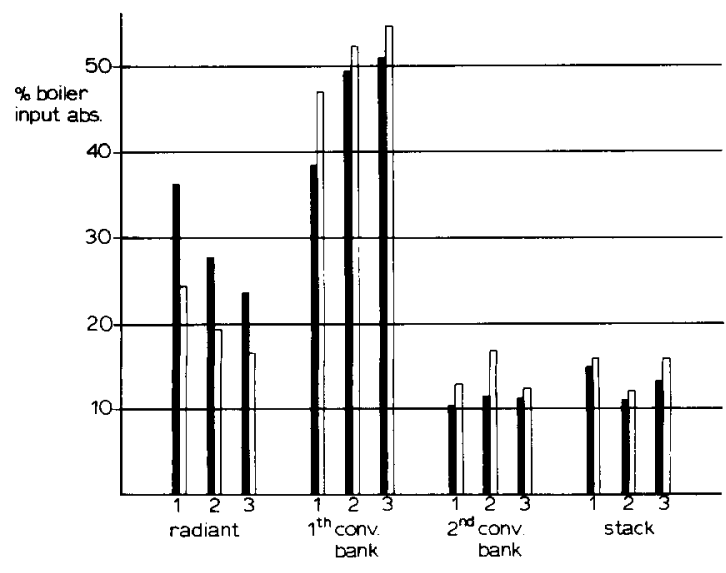

FIG. 13. Heat absorption pattern of a $27 \mathrm{MW}_{\text {th }}$ hot-water boiler model predictions, 1/2/3 as in Fig. 12.
TABLE 3. Steam boiler specifications on natural gas
Nominal rating

Steam pressure

Steam superheat temperature

Feed water temperature

Excess air level

Boiler layout

Superheater surface

Furnace effective heat-transfer surface

Furnace dimensions-height

$\begin{array}{ll}\text { Evaporator surface } & \text { - width } \\ \text {-length }\end{array}$

Economizer surface
$25 \mathrm{MW}_{\text {th }}$ output

$40 \mathrm{bar}$

$490^{\circ} \mathrm{C}$

$105^{\circ} \mathrm{C}$

$10 \%$ case. The flue-gas temperatures are slightly higher when LHV gas is used.

A similar calculation has been carried out for an industrial steam boiler. A single track design was chosen, with similar furnace room dimensions as the hot-water boiler. Superheater, evaporator and economizer dimensions were chosen on the basis of a set of boiler specifications (Table 3 ). For this steam boiler the calculated heat absorption patterns and the performance data are presented in Figs 14-15 and in Table 4 . When the boiler rating is kept at $100 \%$ of its design value, the substitution of natural gas by LHV gas may have the following implications:

-Due to higher flue-gas velocities, the convective heat-transfer coefficient increases and due to the lower flame temperature the radiative heattransfer coefficient drops. As a result of both, the steam superheat temperature may rise.

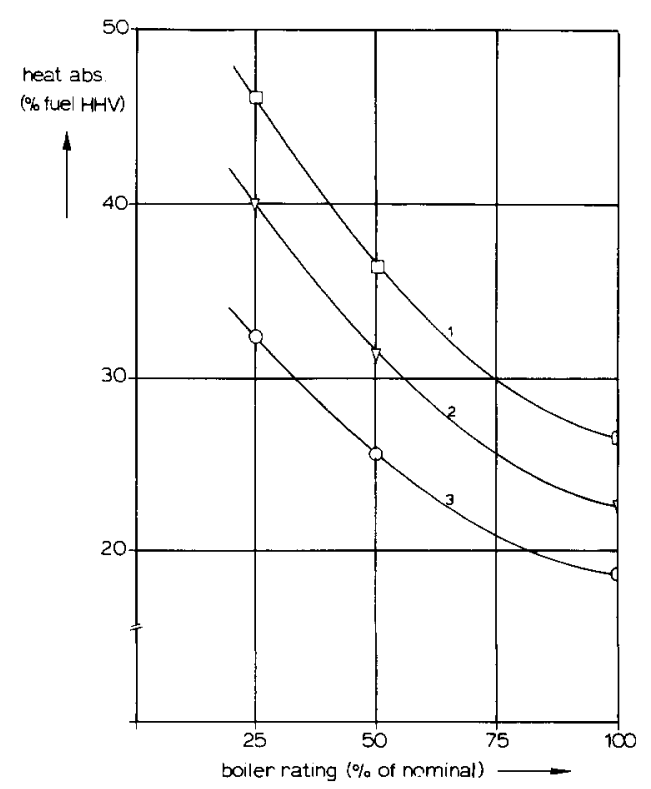

Fig. 14. Radiant section efficiency of a $25 \mathrm{MW}_{\text {th }}$ steam boiler. Model predictions (Tables 3,4): (1) natural gas (Table 1); (2) Wellman air LHV gas, fed at $20^{\circ} \mathrm{C}$ (Table 1); (3) Winkler air LHV gas, fed at $20^{\circ} \mathrm{C}$ (Table 1). 


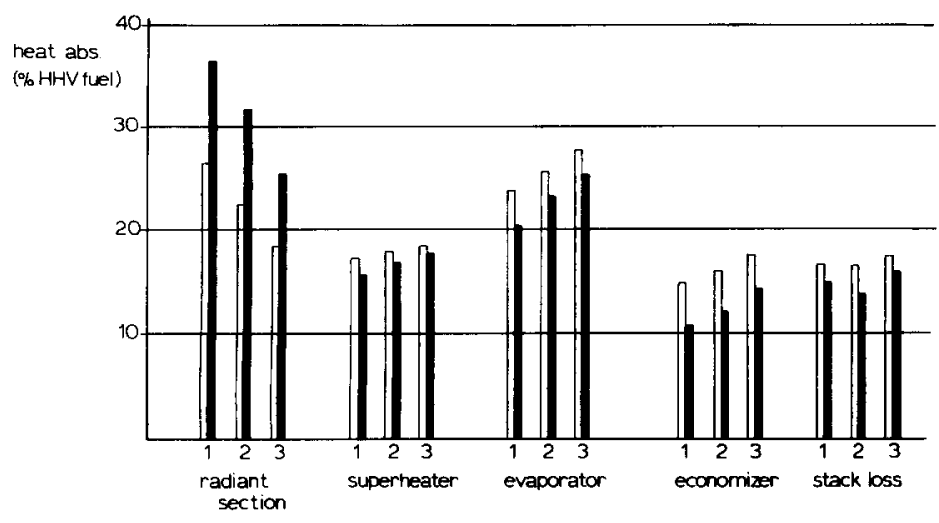

FIG. 15. Heat absorption pattern of a $25 \mathrm{MW}_{\mathrm{th}}$ steam boiler. Model predictions, $1 / 2$ as in Fig. 14. \: $50 \%$ of design load. [.: $100 \%$ of design load.

- The increased heat load of the economizer section of the boiler may give rise to untimely evaporation in this section. This may present a problem, depending upon the specific layout of the boiler.

- On LHV gas the stack gas temperature tends to rise and the boiler efficiency may drop slightly.

A quantitative assessment of the phenomena mentioned above (Table 4) reveals that neither one of them has very dramatic consequences. More serious stack losses can be expected in the case of boilers which are equipped with air preheaters. This is common practice for large utility boilers where they are used to cool down stack gases, typically from $400^{\circ} \mathrm{C}$ to $150^{\circ} \mathrm{C}$. When a natural gas-fired boiler is converted to LHV gas firing, the flue gas-to-air volume ratio approximately increases from 1.1 to 1.8 .
Hence, the original air preheaters will prove totally mismatched. ${ }^{41}$ This results in an efficiency drop, which, for the example given, is presented in Fig. 16. For a close-coupled arrangement this efficiency loss could be reduced by preheating the combustion air of the boiler as well as the air used in the gasification process. For smaller, industrial boilers the problem does not exist because these units are normally not equipped with air preheaters.

\subsection{Retro-fit Considerations}

When existing natural gas or fuel oil-fired boilers are fuelled with coal-derived LHV or MHV gas, various retro-fit modifications may prove necessary. Generally, very few problems are encountered when MHV gas is used ${ }^{41,36}$ and it may be sufficient to modify the burners. When firing LHV gas, additional

TABLE 4. Steam boiler performance on LHV gas and natural gas

\begin{tabular}{|c|c|c|c|c|}
\hline & \multicolumn{2}{|c|}{$\mathrm{LHV}$ gas $\left(5.5 \mathrm{MJ} / \mathrm{Nm}^{3}\right)$} & \multicolumn{2}{|c|}{ Natural gas $\left(35.5 \mathrm{MJ} / \mathrm{Nm}^{3}\right)$} \\
\hline & $50 \%$ load & $100 \%$ load & $50 \%$ load & $100 \%$ load \\
\hline \multicolumn{5}{|c|}{ 1. Heat absorption ( $\%$ of HHV fuel gas input) } \\
\hline radiant section & 29.4 & 21.0 & 36.3 & 26.4 \\
\hline superheater & 17.2 & 18.2 & 15.7 & 17.3 \\
\hline evaporator & 24.2 & 25.6 & 20.6 & 24.0 \\
\hline economizer & 13.2 & 17.1 & 10.9 & 14.9 \\
\hline flue-gas loss & 14.7 & 16.2 & 15.2 & 16.6 \\
\hline heat loss & 1.3 & 0.8 & 1.3 & 0.8 \\
\hline \multicolumn{5}{|l|}{ 2. Steam } \\
\hline production (ton $/ \mathrm{hr}$ ) & 15.2 & 29.8 & 15.7 & 30.6 \\
\hline superheat temp. $\left({ }^{\circ} \mathrm{C}\right)$ & 487 & 502 & 459 & 489 \\
\hline feed-water temp. $\left({ }^{\circ} \mathrm{C}\right)$ & 105 & 105 & 105 & 105 \\
\hline feed-water after economizer $\left({ }^{\circ} \mathrm{C}\right)$ & 210 & 242 & 190 & 224 \\
\hline \multicolumn{5}{|l|}{ 3. Flue gas } \\
\hline flow rate $\left(\mathrm{Nm}^{3} / \mathrm{s}\right)$ & 5.08 & 9.93 & 4.36 & 8.73 \\
\hline temperature $\left({ }^{\circ} \mathrm{C}\right)$ & 127 & 162 & 121 & 155 \\
\hline 4. Output $\left(\mathrm{MW}_{\mathrm{th}}\right)$ & 12.54 & 24.90 & 12.66 & 25.10 \\
\hline
\end{tabular}




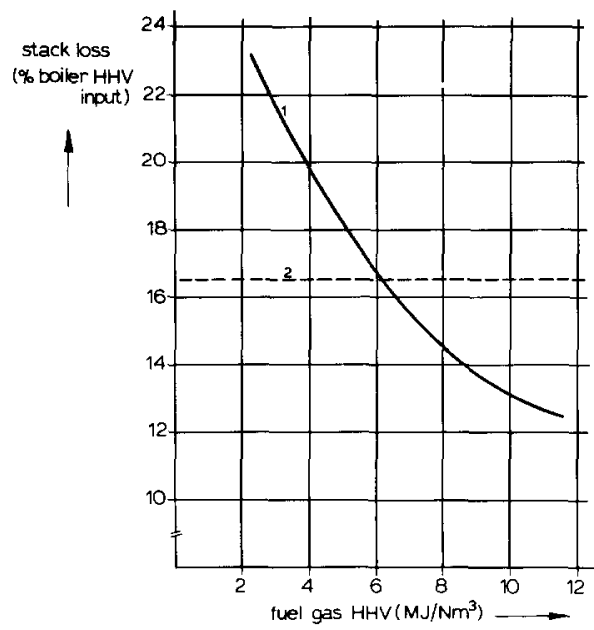

FIG. 16. Stack losses for a steam boiler, designed for naturalgas firing, equipped with air preheaters. (1) When fired with LHV gas, no modifications to the air preheater and fuel gas compositions as in Table 1. (2) When fired with natural gas, air preheater designed to cool stack gases from $400^{\circ} \mathrm{C}$ to $150^{\circ} \mathrm{C}$.

modifications may prove necessary, which can be related to the increased flue-gas flow rate, to flame stability problems and to the necessity to control the flame length. As discussed previously, the burner nozzles and windboxes must be replaced. If a $100 \%$ rating is to be maintained, the induced-draft fans also have to be replaced and provisions may be necessary to cope with the increased furnace-room pressure. The mounting of special LHV burners may require some front-end waterwall rearrangements, as these burners are larger than natural-gas burners. In circumstances where the direct firing of hot fuel gas from the gasifier is feasible, the problems of derating and a reduced boiler efficiency do not exist because in that case the specific flue-gas volume is only slightly higher than in the case of natural-gas firing. A final point which should be considered is the fouling behavior of the fuel gas. Especially when coal-derived fuel gases are fuelled to boilers which are designed to fire natural gas, the narrow tube spacing in the boiler may give rise to deposition of entrained ash-particles. Therefore the amount of ash present in the fuel gas must be quite low.

\section{THE ECONOMICS OF PRODUCING LHV GAS FROM COAL USING FIXED-BED GASIFIERS}

\subsection{Costs of LHVGas}

In order to assess the economic feasibility of producing LHV gas from coal, detailed cost estimates have been made on the basis of available literature data. In these cost analyses only fixed-bed producer gas units are covered, and the capacity range investigated is limited to $2-30 \mathrm{MW}_{\text {th }}$ output. The upper limit of $30 \mathrm{MW}_{\mathrm{th}}$ is chosen on the basis of the maximum unit size of a fixed-bed producer gas unit, which is around $15 \mathrm{MW}_{\mathrm{th}}$ output. Gas costs were established for three cases:

(a) Production of hot, raw product gas, without tar removal or desulfurization.

(b) Production of cold gas, without desulfurization.

(c) Production of cold, desulfurized gas, including tar and solids removal.

These cases cover essentially all situations that can be found in industrial practice. The above subdivision is based upon the assumption that currently no hot gas desulfurization systems are available. Consequently case (c) applies whenever the existing environmental legislation requires some form of sulfur emission control. Case (b) covers those applications where the fuel gas has to be delivered cold. This may apply when the fuel gas must be compressed, for instance in the case of gas turbines, or when a high efficiency fines removal system is necessary. Application of the fuel gas in dual-fuel or gas engines is also covered by case (b). Finally, case (a) covers the direct use of hot fuel gas in kilns, furnaces and boilers, when no form of desulfurization is required.

The gas cost analysis is based upon available data for counter-current producer gas units. For reasons of comparison, various calculations have also been made for co-current gasifiers, on the basis of pilot plant data. ${ }^{25}$ All cost data will be presented in mid-1983 US dollars.

\subsubsection{Plant layout}

The general layout of a gasifier which is installed in a close-coupled arrangement, has been presented previously in Fig. 8. A typical plant would consist of three major modules, namely the solid handling systems, the gasifier and the gas-treating section.

Coal handling starts after the unloading of coal at an outdoor storage pile. From this long-term storage, coal is fed to a size-screening operation and to a storage bin. Subsequently, coal is transported to a top hopper on the coal gasifier. Through this lock hopper, often a rotary drum feeder, coal is introduced into the gasifier vessel. Ash is withdrawn from the bottom of the gasifier and discharged into an ash storage bin.

The gasifier consists of a vertically positioned cylindrical vessel, which is usually partly insulated and partly water-cooled. Included in the gasifier module are the ash grate, ash removal systems, reactor internals, instrumentation and control equipment, a main gas header and the plant structures. The gasification air is supplied by an air-fan and passed over the jacket water in order to take up a certain amount of steam. Hot product gas from the gasifier is passed through a cyclone to remove coarse solid particles. Subsequently it is cooled in a direct-contact water scrubber and a shell-and-tube heat exchanger. The remaining tar mist is eliminated in an electrostatic precipitator. The quench water from the scrubbing system must be treated prior to disposal. Cold gas is transported to a low-temperature desulfurization system. Often, a Stretford unit, consisting of a liquid 
TABLE 5. Equipment costs, size exponents and field installation factors for fixed-bed gasifiers

\begin{tabular}{lccc}
\hline & $\begin{array}{c}\text { Equipment costs } \\
\text { at } 20 \mathrm{MW}_{\mathrm{h}} \text { size } \\
\left(10^{3} \mathrm{US} \$\right)\end{array}$ & $\begin{array}{c}\text { Size exponents } \\
>5 \mathrm{MW} /<5 \mathrm{MW}\end{array}$ & $\begin{array}{c}\text { Field installation } \\
\text { factors }\end{array}$ \\
\hline 1. Storage & 96 & $0.85 / 0.70$ & 1.2 \\
2. Coal handling & 192 & $0.70 / 0.60$ & 2.1 \\
3. Gasifiers & 400 & $0.85 / 0.75$ & 1.8 \\
4. Cyclones & 48 & $0.80 / 0.70$ & 1.2 \\
5. Ash handling & 42 & $0.70 / 0.60$ & 1.9 \\
6. Air compression & 160 & $0.65 / 0.75$ & 1.6 \\
7. Emergency flame & 59 & 0.60 & 2.5 \\
8. Cooling tower & 148 & $0.60 / 0.50$ & 1.6 \\
9. Heat recovery & 130 & $0.70 / 0.60$ & 1.9 \\
10. Gas scrubbing & 43 & $0.65 / 0.55$ & 1.9 \\
11. Electrostatic precipitation & 176 & $0.75 / 0.65$ & 1.9 \\
12. Sour water treatment & 160 & 0.60 & 1.2 \\
13. Desulfurization & 690 & 0.5 & 1.6 \\
14. Utilities/facilities & $12 \%$ of the equipment costs & & \\
\hline
\end{tabular}

absorption step and a subsequent oxidation step to produce elemental sulfur, is employed.

The outside battery limits of the installation cover the provisions necessary for supply of utilities, a cooling tower, a control room and various safety provisions. The capital investments presented in the next section do not include buildings or infrastructural arrangements, like roads.

\subsubsection{Capital investments}

The procedure used herein to calculate the total plant investment has basically been adopted from Guthrie. ${ }^{47}$ The general approach is to obtain equipment costs, size exponents and field installation factors for each of the major equipment items involved. The equipment costs have been obtained from various literature sources on counter-current producer gas units. ${ }^{33,48,50,51}$ The cost data in these sources have been found to be reasonably consistent. Minor differences in the plant layout between the various references have been neglected. All cost data are updated to a mid- 1983 cost level on the basis of an annual cost increase of $5 \%{ }^{52}$ In the case of general equipment items, or when no detailed specifications were available, cost data from Guthrie ${ }^{47}$ were taken. Field installation costs were assessed on the basis of data from Foster Wheeler. ${ }^{4,50}$

The results of these calculations are presented in Table 5. The direct equipment costs were increased

TABLE 6. Project indirect costs

\begin{tabular}{ll}
\hline Supervision during construction & $3 \%$ \\
Interest during construction & $2 \%$ \\
Overhead during construction & $3 \%$ \\
Engineering and design & $7 \%$ \\
Subcontractors fee & $8 \%$ \\
Insurance and tax & $2 \%$ \\
Contingency allowance & $8 \%$ \\
& \\
& $33 \%$ of direct \\
& investment costs
\end{tabular}

with a moderate $12 \%$ for utilities and facilities, assuming that the gasifier is incorporated in an existing plant. In this way the field-installed equipment costs were obtained, to which indirect project costs of $33 \%$ were added, as detailed in Table 6.

The total capital investments are presented in Fig. 17. For co-current gasifiers the costs for tar removal and sour water treating are omitted. The capital-cost estimation sketched above allows a reliable scale down of the plants for which literature data are available. As is shown by the present data, overall size exponents may vary significantly for different plant size ranges and it is therefore questionable whether overall size exponents should be used in capital cost estimations for producer gas units. This was also concluded elsewhere. ${ }^{51}$ The capital costs for factory assembled package gasifiers could probably be 10 $30 \%$ lower, if such units are quantity produced. How-

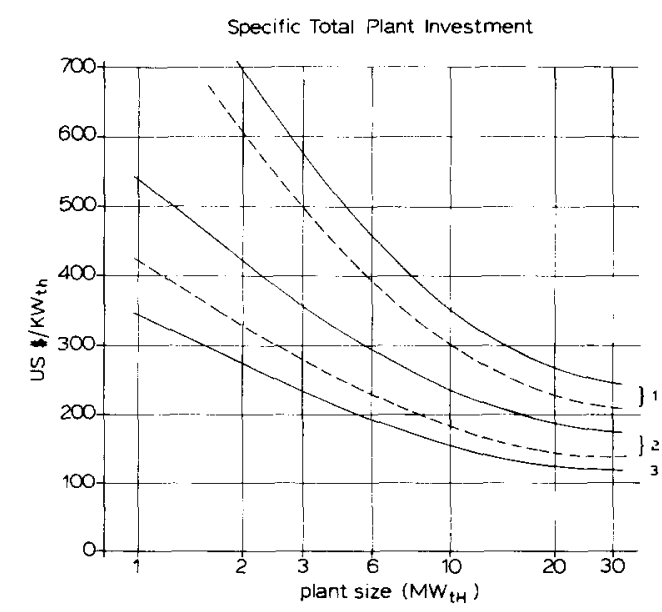

FIG. 17. Specific total capital investments for fixed-bed producer gas units: (1) producing cold, desulfurized gas; (2) producing cold gas; (3) producing hot, untreated gas (cocurrent and counter-current gasifiers). --.---: Co-current operation;-— : counter-current operation. 
TABLE 7. Plant utility requirements coal use and by-products

\begin{tabular}{|c|c|c|c|c|}
\hline Case & 1 & 2 & 3 & 4 \\
\hline Coal use (GJ/MW hr) & 4.83 & 4.48 & 4.07 & 3.96 \\
\hline Ash production (ton/MW hr) & 0.0177 & 0.0164 & 0.0149 & 0.0149 \\
\hline Water use $\left(\mathrm{m}^{3} / \mathrm{MW} \mathrm{hr}\right)$ & 1.0 & 0.4 & 0.6 & 0.2 \\
\hline Tar production (kg/MW hr) & 10.6 & - & - & - \\
\hline Sulfur production $(\mathrm{kg} / \mathrm{MW} \mathrm{hr})$ & 1.8 & 1.6 & - & - \\
\hline By-product heat (GJ/MW hr) & 0.38 & 0.36 & - & - \\
\hline Electricity consumption (GJ/MW hr) & 56.4 & 50 & 15 & 15 \\
\hline
\end{tabular}

All data are given per $\mathrm{MW}_{\mathrm{th}}$ total energy output.

Case 1: counter-current, cold gas

Case 2: co-current, cold gas

Case 3: counter-current, hot gas

Case 4: co-current, hot gas.

ever, at this moment gasifiers are typically installed on site and thus this option is ignored.

\subsubsection{Operating costs}

The operating costs for a gasification plant include the expenses for fixed and variable maintenance, utility costs, cost of coal, labour costs and expenses for ash disposal. Any tar or by-product steam are incorporated as credits. Utility requirements for countercurrent and co-current fixed-bed gasifiers have been estimated on the basis of various sources, ${ }^{50,48,25}$ see Tables 7 and 8 . The costs of coal, utilities and ash disposal are taken for the Dutch situation, but they can be considered typical for Western Europe. This may not apply for the costs of electricity, which vary significantly. To some extent the operating costs will depend on the type of coal that is processed and therefore a typical coal was assumed, containing $10 \mathrm{wt} \%$ ash, $1 \mathrm{wt} \%$ sulfur and having a heating value of $27.3 \mathrm{MJ} / \mathrm{kg}$. The tar yield upon devolatilization is taken to be $6 \%$ of the coal weight.

\subsubsection{Gas cost analysis}

On the basis of the capital and operating costs for fixed-bed gasifiers, the gas production costs can be assessed. These costs will be presented as first year costs, in order to prevent any speculations about the future energy prices. On the basis of the financial data given in Table 9, the discounted cash-flow rate of return before taxation is estimated to be $20 \%$. The total plant life is conservatively estimated to be $15 \mathrm{yr}$, though most manufacturers claim a larger plant life, ranging from 20 to $25 \mathrm{yr}^{18,48}$

TABLE 8. Operating and utility costs

\begin{tabular}{|c|c|}
\hline Fixed maintenance & $1.5 \%$ of total investments $/ \mathrm{yr}$ \\
\hline Variable maintenance & $\begin{array}{l}2.0 \% \text { of total investments } / y r \text { at } \\
\text { full capacity }\end{array}$ \\
\hline Operating labour & $0.75 \%$ of total investments/shift \\
\hline Steam costs & $15.4 \$ /$ ton \\
\hline Electricity costs & $65 \$ / \mathrm{MW} \mathrm{hr}$ \\
\hline Tar credit & $115 \mathrm{~S} /$ ton \\
\hline Ash disposal costs & $11.5 \$ /$ ton \\
\hline By-product heat credit & $4.6 \$ / G J$ \\
\hline Desulfurization chemicals & 84 \$/ton sulfur \\
\hline Coal & $74 \$ /$ ton $=2.71 \$ / G J$ \\
\hline
\end{tabular}

The results of the gas cost calculations are presented in Fig. 18 for various plant sizes and plant load factors. For reasons of comparison, the approximate natural-gas price range for Western Europe has been included.

From the data presented in Fig. 18 it can be observed that a large difference exists between the costs of cold, desulfurized gas on the one hand and hot, raw gas on the other. With the assumed coal price level of $2.7 \mathrm{US} \$ / \mathrm{GJ}$ (2.85\$/MMBtu), cold, desulfurized gas is only competitive with natural gas for large unit capacities and high gasifier load factors (Figs $18 \mathrm{e}, \mathrm{f})$. Even in countries with a comparatively high natural-gas price level, the return on investment may be marginal. Hence, fixed-bed producer gas will in general only be applied to process low-sulfur coal. The costs of generating cold gas are substantially higher than those for the production of hot gas. This can largely be attributed to the necessity of removing tarry components, when the product gas is cooled. This is an expensive operation, and it illustrates the attractiveness of producing a low-tar product gas in a single operation. On the basis of the cost data presented it can be concluded that the generation of LHV gas is especially attractive in those cases where hot gas can be utilized directly (Figs 18a,b). If this is not feasible, the market potential for LHV-gasifiers is limited to fairly large unit capacities and high plant load factors.

\subsection{Competitiveness of LHV Gas as compared to MHV Gas and Direct Coal Firing}

The competitiveness of LHV gas is largely governed by local prices of natural gas and fuel oil. However, a major part of the industrial fuel consumption is

TABLE 9. Financial parameters

\begin{tabular}{ll}
\hline Plant life & $15 \mathrm{yr}$ \\
Income tax & $48 \%$ \\
Equity capital & $40 \%$ \\
Return on equity & $14 \%$ after taxation \\
Debt rate & $8 \%$ \\
D.C.F.R.R. & $10 \%$ after taxation \\
Investment tax credit & $22 \%$ \\
Depreciation policy & $15 \mathrm{yr}$, linear \\
\hline
\end{tabular}



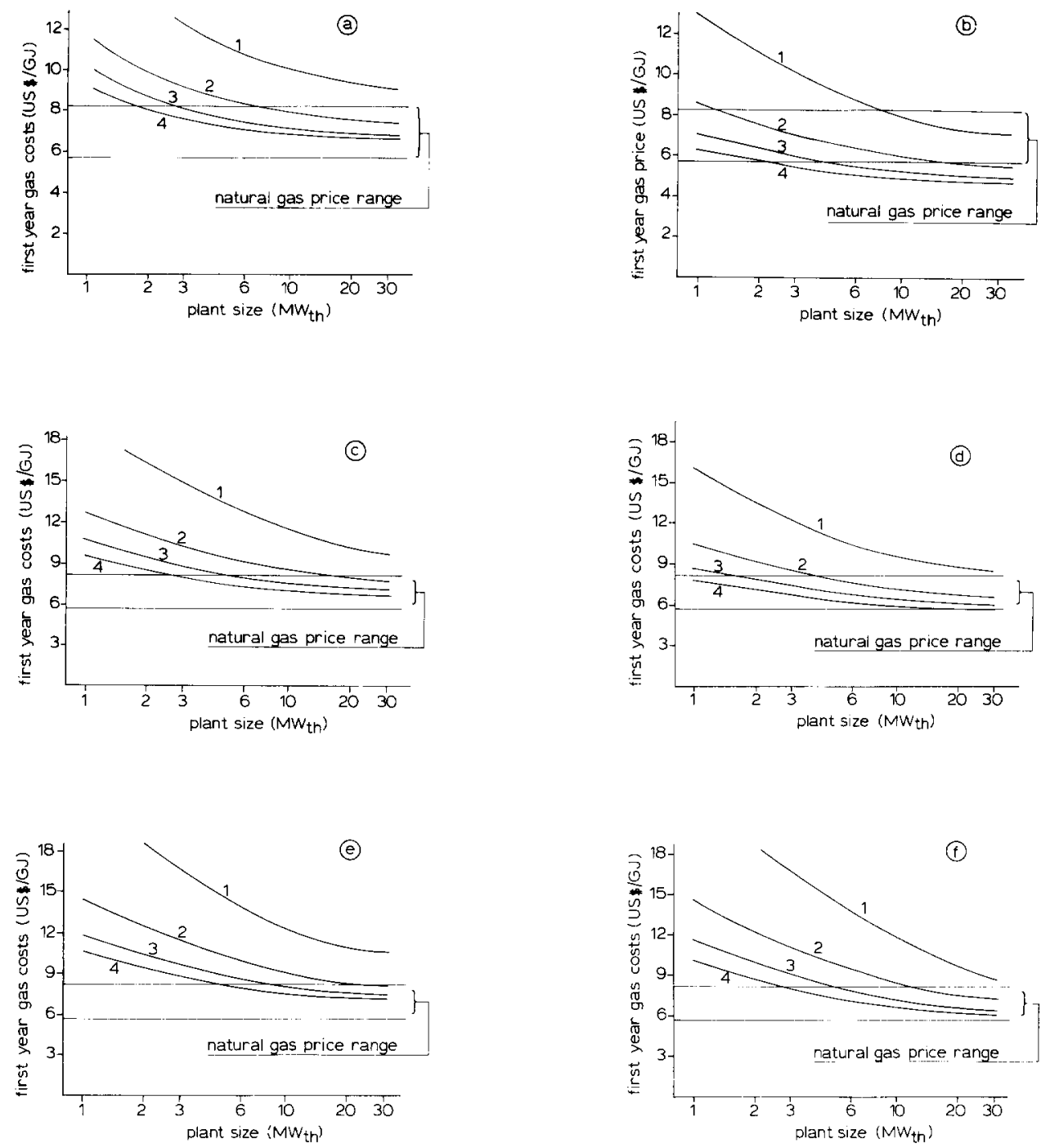

FIG. 18. First year gas costs for fixed-bed producer gas units, 1/2/3/4: 1800/3600/5400/7200 hr/a. (a) Counter-current gasifiers; hot, raw gas. (b) Co-current gasifiers; hot, raw gas. (c) Counter-current gasifiers; cold gas. (d) Co-current gasifiers; cold gas. (e) Counter-current gasifiers; cold, desulfurized gas. (f) Cocurrent gasifiers; cold, desulfurized gas.

utilized for steam-raising purposes. In this market, LHV-gasifiers may also have to compete with the direct utilization of coal in stoker-fired or fluidizedbed boilers. The costs of producing steam with small stoker-fired and fluidized-bed boilers have been compared to steam-raising costs when hot LHV gas is fueled to a conventional gas-fired boiler. The capital investments and operating costs for the former were

TABLE 10. Capital investments of boilers

\begin{tabular}{lcc}
\hline \multicolumn{1}{c}{ Type } & $\begin{array}{c}\text { Net investment } \\
\text { after tax credit } \\
\text { at } 1 \mathrm{MW}_{\mathrm{th}} \text { input }\end{array}$ & $\begin{array}{c}\text { Size } \\
\text { exponent }\end{array}$ \\
\hline Gas-fired, water tube & $210,000 \$$ & 0.6 \\
Stoker-fired, water tube & $380,000 \$$ & 0.6 \\
Fluidized-bed, water tube & $550,000 \$$ & 0.6 \\
\hline
\end{tabular}

estimated on the basis of data from Dutch and German equipment manufacturers, see Tables 10 and 11. Using the same financial parameters as before, the first year steam-raising costs can be calculated, see Fig. 19. In general, the costs of a newly erected gasifier/boiler arrangement are high as compared to the costs of stoker-fired and fluidized-bed boilers.

TABLE 11. Operational costs of boilers

\begin{tabular}{ll}
\hline Maintenance & $\begin{array}{l}4 \% \text { of total investments/a } \\
\text { Labour }\end{array}$ \\
Insurance & $0.5 \%$ of total investments/a \\
& \\
Efficiency & \\
gas-fired & $92 \%$ \\
stoker-fired & $78 \%$ \\
fluidized-bed & $85 \%$
\end{tabular}




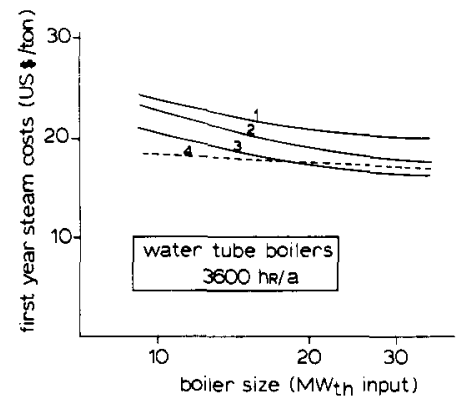

FIG. 19. First year steam production costs for water-tube boilers, for an operating time of $3600 \mathrm{hr} / \mathrm{a}$ : (1) countercurrent gasifier, delivering hot, raw gas to an existing boiler; (2) fluidized-bed boiler; (3) stoker-fired boiler; (4) as (1), no capital charges for the boiler.

However, it should be mentioned here that in particular the capital investments for fluidized-bed boilers are liable to a significant uncertainty. Nevertheless, at present we must conclude that retrofitting a LHV-gasifier to an existing gas-fired boiler is an attractive option only when premature scrapping of a fairly new boiler can be prevented in this way.

In future, MHV gas might become available to industrial consumers. It would then be relevant to establish the cost ratio for LHV gas, produced on-site, and MHV gas, delivered by pipeline. MHV gas would typically be produced by a medium or large-scale, centralized gasification plant, and it would be transported to various industrial sites. The capital investments involved in the erection of MHV gas plants have been updated from various literature sources. ${ }^{49,50}$ The utility and ash-disposal costs given in these literature sources have been corrected to unit costs as given in Table 8. It seems reasonable to assume that the advanced and larger MHV gas plants are more flexible as far as the coal feed is concerned. Also, the coal transportation costs may be lower. Therefore a coal price of $2.3 \mathrm{US} \$ / \mathrm{GJ}$ was assumed for these installations. All other cost data, such as the labour and maintenance costs were updated to a mid1983 cost level, assuming a mean rate of increase of these costs of $5 \% / \mathrm{yr}$. The corrected costs of facilities and services are listed in Table 12. The financial parameters, listed in Table 9, were again utilized to

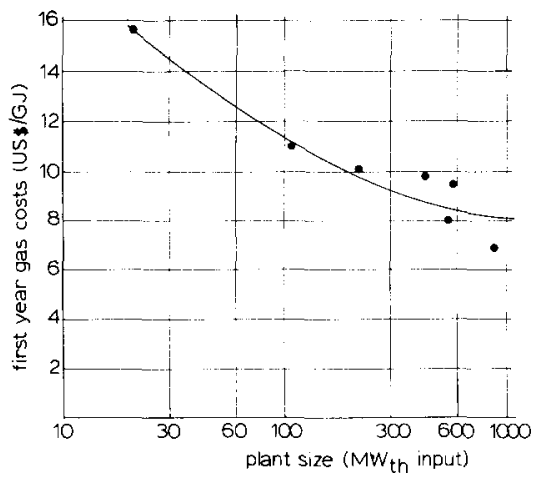

FIG. 20. First year gas costs for MHV plants, see Table 12.

$$
\begin{aligned}
& \text { - } 7200 \mathrm{hr} / \mathrm{a} \text { operating time } \\
& \text { - coal costs: } 2.3 \$ / \mathrm{GJ} \\
& \text { - production of cold desulfurized gas. }
\end{aligned}
$$

calculate first-year gas costs. The MHV gas is produced at pipeline quality standards, including fines and sulfur removal, and drying. The gas cost data in Fig. 20 do not include any pipeline transportation costs. Despite the lower coal price and the high plant load factor, assumed to be $90 \%$, MHV gas cannot compete with LHV gas, generated on-site. Only when MHV plants have a very large unit size, may this situation change (Fig. 20). However, in that case the gas transportation distance may be long and the gas distribution costs may therefore add considerably to the total gas price. Hence, it can be concluded that MHV gas will in general not be a serious competitor for LHV gas, certainly not for on-site gas production on a low and intermediate scale.

\section{SUMMARY AND CONCLUSIONS}

The re-introduction of coal as an industrial fuel may be facilitated by the on-site generation of Low Heating Value gas from coal, using air gasification. For small- and medium-sized plants, fixed and fluidized-bed gasifiers seem to be most suited for this job. At present only fixed-bed gasifiers are commercially proven however. A considerable experience has been gained with these gasifiers. In general the use of LHV gas as a substitute for natural gas requires only

\begin{tabular}{|c|c|c|c|c|}
\hline Plant type & $\begin{array}{c}\text { Capacity } \\
\left.\text { (MW }_{\text {th }} \text { input }\right)\end{array}$ & $\begin{array}{l}\text { Capital investments } \\
\text { (MM US\$) }\end{array}$ & $\begin{array}{l}\text { Operating costs* } \\
\text { (MM US } \$ / a)\end{array}$ & $\begin{array}{l}\text { Coal costs } \dagger \\
(\mathrm{MM} \mathrm{US \$ /a)}\end{array}$ \\
\hline Lurgi, $\mathrm{O}_{2}^{49}$ & 540 & 247 & 13.25 & 35.4 \\
\hline Koppers, $\mathrm{O}_{2}^{49^{2}}$ & 570 & 289 & 21.60 & 37.4 \\
\hline Texaco, $\mathrm{O}_{2}^{50^{2}}$ & 880 & 333 & 22.20 & 57.7 \\
\hline \multirow[t]{4}{*}{ Koppers, $\mathrm{O}_{2}^{50}$} & 21.6 & 32 & 1.51 & 1.4 \\
\hline & 108 & 81 & 7.55 & 7.0 \\
\hline & 216 & 135 & 15.10 & 14.0 \\
\hline & 432 & 248 & 30.2 & 28.0 \\
\hline
\end{tabular}
moderate equipment modifications in the case of kilns

TABLE 12. Capital investments and costs of service of MHV gas plants, delivering cold desulfurized gas

\footnotetext{
* Operating time: $7200 \mathrm{hr} / \mathrm{a}$
}

$\uparrow$ Coal costs: $2.3 \$ / \mathrm{GJ}$. 
and furnaces. Only when high furnace temperatures are required, are some additional provisions necessary. If LHV gas is to be fired in existing boilers, various retrofit modifications may prove necessary and a moderate drop in the boiler rating and efficiency may be anticipated. For the market situation in Western Europe, the production of desulfurized LHV gas from coal is in general not economically feasible. In contrast, the production of LHV gas from lowsulfur coal, not demanding any desulfurization, may be competitive compared to natural-gas firing. It does not seem likely that MHV gas, should it become available, presents a serious competitor for LHV gas. The on-site gasification of coal to LHV gas, and the subsequent utilization of this gas may prove more expensive than the direct combustion of coal. Hence, gasification seems to be attractive only in those cases where direct coal combustion is not feasible from a technical or environmental point of view, or when the introduction of coal-combustion equipment is accompanied by premature scrapping of existing installations. One may think of the use of LHV gas in tile and reactive-lime furnaces and various kinds of melting, drying and pre-heating furnaces. Especially if these units can be fired with hot gas from the gasifier, the reduction of the fuel costs may be substantial.

Acknowledgements - The authors gratefully acknowledge the financial support obtained for the present work from Shell Coal International Ltd., London and the Netherlands Energy Research Foundation, E.C.N. Part of the work was carried out in cooperation with T.N.O., the Netherlands Organization for Applied Scientific Research. We are indebted to R. W. Angenent and R. H. Slingerland for carrying out the vast part of the calculations.

\section{REFERENCES}

1. Littlewood, K. Gasification: Theory and Application. Prog. Energy Combust. Sci. 3, 35 (1977).

2. Lowry, M. H. Chemistry of Coal Utilization; Suppl. Vol. John Wiley, N.Y. (1963).

3. Fixed Bed Gasification; Topical Report. Morgantown Energy Technology Center, DOE/METC/SP-184/ UC90C (1981).

4. KING, W. E. H. Coal Gasification. Fuel 60, 803 (1981).

5. Patel, J. G. The U-Gas Process. Energy Res. 4, 149 (1980).

6. Schad, M. K. and HafKe, C. F. Coal Handling Practices: Recent Developments in Coal Gasification. Chem. Engng Prog. 79, 45 (1983).

7. Franken, G., Adl.HOCH, W. and $\mathbf{K O C H}$, W. Herstellung von Synthesegas aus Braunkohle. Chemie-Ingr-Tech. 52, $324(1980)$

8. Schora, F. C. and Bodle, F. W. Coal Gasification Technology Overview. Adv. Coal Utilization Technology (May 1979).

9. Banchik, I. N., Subramaniam, T. K. and Marten, J. H. Pressure Reaction Cuts Gasification Costs. Hydrocarbon Processing 121 (March 1977).

10. Schlinger, W. G. Coal Gasification Developments and Commercialisation of the Texaco Coal Gasification Process. Energy Res. 4, 127 (1980).

11. VAN DeR Burgt, M. J. and ECKstein, O. Development of the Shell Coal Gasification Process, 27 DGMKHaupttagung, Aachen (1982).
12. Michaels, H. J. and Leonard, H. F. Hydrogen Production via K-T Gasification. Chem. Engng Prog. 85 (1978).

13. Low and Medium Btu Gas. The WD/GI Process. Symposium of the Institute of Gas Technology, Efficient Use of Fuels in Metallurgical Industry 203 (1974).

14. RaIney, D. L. New Developments in the Production of Gas from Coal. A. Mtg Ass. Pulp Paper Ind. 189 (1982).

15. Kolesh, V. A., Early, W. P. and Jones, F. L. Low Btu Gasification of Northern Plains Lignite in a Commercial Sized Unit. Proc. Am. Pwr Conf. 43, 970 (1981).

16. Broeker, R. J. and Bress, D. F. Operations of a Two Stage Fixed Bed Coal Gasifier at the University of Minnesota. Coal Technology'79, Houston (1979).

17. Deacon, J. S. Commercial Application of Low-Btu Coal Gasification to Combined Cycle Electricity Generating Plants Using the Kilngas Process. 9th Energy Technology Conference 620 (1982).

18. Culbertson, R. W. and K Asper, S. New Look at the Small Gasifier. Trans. Soc. Min. Engrs, A.I.M.E. 266, 1904 (1979).

19. Woodmansee, D. E., Floess, J. K. and Furman, A. H. Gasification of Illinois 6 Coal in an Advanced Fixed-Bed Gasifier. Coal Process. Technol. VI, 231 (1980).

20. H.P.I. Construction Boxscore. Hydrocarbon Process. 2 , 21 (1983).

21. Lohmann, G. and RoebKe, G. Das Kohlevergasungsprojekt Dorsten, Lurgi- Ruhr 100. Bisherige Betriebserfahrungen. Gas-u. WassFach, Gas-Erdgas 8, 359 (1980).

22. Rudolph, P. F. H. and Herbert, P. K. Conversion of Coal to High Value Products. Presented at the Chem. Engng Congress, London (14-15 May, 1975).

23. Bauer, J., Dorstewitz, U., Kaiman, W. and Schauerte, H. The K.G.N. Fixed Bed Gasifier and the Planned Gasworks "Riedelland." Adv. Coal Util. Technol. IV, 169 (1981).

24. Rambush, N. E. Modern Gas Producers. Benn Brothers, London (1923).

25. BLIEK, A. Mathematical Modeling of a Cocurrent Fixed Bed Coal Gasifier. Ph.D. thesis, Twente University of Technology, The Netherlands (1984).

26. Reed, T. B., Jantzen, D. E., Cokcoran, W. P. and Witholder, R. Technology and Economics of Close Coupled Gasifiers for Retro-fitting Gas/Oil Combustion Units to Biomass Feedstock. Retrofit '79, Proceed. Workshop on Air Gasification, 8-1, SERI/TP-49-183 (1979).

27. Quentin, G. H. Control Analysis of Gasification/Combined Cycle Power Plants. Engng Fdn Conf. Process Control (1981).

28. JoNES, F. L. and Rick, N. Gasification of Western Coal. Fuel for Thought. Advances in Coal Utilization Technology IV, Denver (1981).

29. Pollutant Emission from Dirty Low- and Medium Btu Gases. Institute of Gas Technology, USA, NTIS pb-288 234 (1978).

30. Environmental Implications of Small Fixed Bed Gasifiers for Industry. Oak Ridge National Laboratory, ORNL/TM-7361 (1981).

31. Satter, G. W. and Cushman, R. M. Preliminary Environmental Assessment of the University of Minnesota-Duluth Coal Gasifier. Oak Ridge National Laboratory, ORNL/TM-7728 (1981).

32. Environmental Aspects of Retrofitting Two Industries to Low- and Intermediate-Energy Gas from Coal. Batelle Columbus Laboratories, NTIS $p b-253946$ (1976).

33. Stewart, J. E. On-Site Synthetic Fuel Gas Generation and Combustion. Proceedings of the 1981 Engineering Conference, no. 1, p. 99 (1981).

34. Putnam, A. A., Merryman, E. L., Ball, D. A. and Barrett, R. E. Gas from Coal: Combustion Properties and Utilization in industrial Burners. 1976 Meeting Central States Section of the Combustion Institute, Ohio, USA. 
35. Putnam, A. A., Levy, A. and Briceland, C. L. Correlation of Stability Limits of Industrial Premix Burners with Laminar Flashback Velocity Gradients for Three Fuels. Combust. Sci. Technol. 29, 287 (1982).

36. Development of Combustion Data to Utilize Low Btu Gases as Industrial Process Fuels. Final Rept. Institute of Gas Technology, USA, NTIS/FE-2489-48, uc $90 \mathrm{c}$.

37. W AIBEL, R. T. Retrofitting Industrial Furnaces to Use Low- and Medium Btu Gases. Symposium, New Fuels and Advances in Combustion Technologies, p. 33, New Orleans, CONF 790337 (1979).

38. Low/Medium Btu Coal Gasification Assessment Program for Specific Sites at Two New York Utilities. Prepared by N.Y. State ERDA, DOE/FE/20223-2/uc $90 \mathrm{c}$ (1982).

39. Assessment of the Capability of Firing Clean Low Btu Gases in existing Coal, Oil and Gas Fired Steam Generators. Prepared by Combustion Engineering Inc., NTIS/ $P B-248328$ (1975).

40. Low/Medium Btu Coal Gasification Assessment of Central Plant for the City of Philadelphia, Pennsylvania. Prepared by Philadelphia Gas Works, DOE/FE/20222-2 (Feb. 1981).

41. WINSOR, L. Technical Considerations in Switching to Gas Derived from Coal in Utility Boilers. Adv. Coal Utilization Technol. IV, Denver, Colorado (1981).

42. NigRo, J. C. Firing an Iron-Ore Pelletizing Kiln with Low-Btu Gas from Lignite. Bureau of Mines, Rept. of Investigations No.8670 (1982).
43. Brown, T. D. Coal Gasification-Combined Cycles for Electricity Production. Prog. Energy Combust. Sci. 8, 277 (1982).

44. Power Cycle Evaluation of the C-E Coal Gasification Process. Presented at the American Power Conference, CE publ. TIS-6210 (1979).

45. Hottel, H. C. Radiative Transfer in Combustion Chambers. J. Inst. Fuel 34, 220 (1961).

46. Burner Design Criteria for NOx Control from Low Btu Gas Combustion, Vol. II: Elevated Fuel Temperature. Institute of Gas Technology, USA, PB 280 199/EPA 600-7-77-094b (1977).

47. Guthrie, K. M. Data and Techniques for Preliminary Capital Cost Estimation, Modern Cost Engineering Techniques (H. POPPER, ed.), McGraw-Hill (1970).

48. Verma, A. Small Industrial Scale Coal Gasifiers, p. I: Energy Sources 5, 381 (1981); p. II: Energy Sources 5, 411 (1981).

49. Verma, A. and Read, P. J. Small Scale Coal Gasification Plants. Energy Sources 4, 281 (1979).

50. Low and Medium Btu Gas-Fired Boilers with Associated Gasification Plants, phase II, Final Report. Prepared by Foster Wheeler, Oak Ridge National Laboratories, ORNL/Sub-80/13847/2 RN 249 (1981).

51. ECKhart, M. T. and ChuRCH, R. L. Market Outlook for Low and Medium Btu Coal Gasification. 8th Energy Technology Conference, p. 81 (1981).

52. Chemical Engineering Plant Cost Index. Chem. Engng 90, no. 13 (1983).

53. Gaz Integrale Company information. 